Filetto, F.; Macedo, R.L.G. Desenvolvimento de indicadores de sustentabilidade para o Ecoturismo em Unidades de Conservação. Revista

\title{
Desenvolvimento de indicadores de sustentabilidade para o Ecoturismo em Unidades de Conservação
}

\section{Sustainable Development Indicators for Ecotourism in Protect Areas}

\author{
Ferdinando Filetto, Renato Luiz Grisi Macedo
}

\begin{abstract}
RESUMO
O tema central deste trabalho refere-se a indicadores de sustentabilidade. Os objetivos foram: propor indicadores de sustentabilidade para o ecoturismo, considerando os componentes ambiental, social e econômico, considerados como indicadores biofísicos (ambiental) e socioeconômicos (social e econômico). Utilizouse de um roteiro para a definição dos indicadores de sustentabilidade, identificandose essas categorias significativas: recursos endógenos, operação do sistema endógeno, recursos exógenos e operação dos sistemas exógenos. Foram determinados 98 indicadores, sendo que 19 foram do elemento natural (explicitados como sendo a água, o solo, o ar, a flora e a fauna), 10 do elemento cultural (apresentados como patrimônio histórico, artístico, cultural e paleo-antropoarqueológico), 25 do elemento social e 4 do elemento econômico.
\end{abstract}

PALAVRAS-CHAVE: Indicadores; Sustentabilidade; Ecoturismo; Unidades de Conservação.

\section{ABSTRACT}

The main subject of this work refers to sustainable indictors. The objectives were: propose sustainable indicators for the ecotourism, considering social, economic and environmental components, considered as indicating biophysical (environmental) and socioeconomics (social and economic). A script was used for the definition of the sustainable indicators, identifying these significant categories: endogenous resources, endogenous operation system, exogenous resources and operation of exogenous resources. Were determined 98 indicators, wherein 19 were of the natural element (explained as water, soil, air, the flora and fauna), 10 of the cultural element (submitted as historical, artistic, cultural and paleo-antropo-archaeological heritage), 25 of social element and 4 of the economic element.

KEYWORDS: : Indicators; Sustainable; Ecotourism; Protect Areas.

\section{Introdução}

A questão da sobrevivência humana sempre foi permeada pela necessidade do conhecimento do ambiente e de suas relações, mesmo que de forma primitiva. Conhecer as forças da natureza, os períodos de frutificação e maturação de vegetais e as melhores épocas para caça eram essenciais. Mesmo que os avanços tecnológicos pareçam distanciar a humanidade da natureza, esta dependência continua. A valoração dos "produtos e serviços" da natureza somente são considerados quando ocorre uma crise. Até então, imagina-se que sejam ilimitados ou, de certa forma, substituíveis por inovações tecnológicas, apesar de evidências que indicam o contrário. 
Os principais recursos do ecoturismo são aqueles provenientes do ambiente natural e cultural. No caso dos recursos naturais, é, muitas vezes, a qualidade dos recursos que oferece a atração e o local torna-se secundário. Seu apelo é tanto nacional quanto internacional. Tradicionalmente, os recursos baseados em água, sejam litorais ou lagos, têm sido os mais importantes e ainda o são, mas com o aumento na quantidade de férias de que as pessoas desfrutam, o campo e as paisagens pitorescas têm tido maior utilização. Informações da PNUMA (2011) informam que o ecoturismo cresce mundialmente em torno de $34 \%$ ao ano e três vezes mais do que o turismo convencional. $\mathrm{O}$ aspecto mais comum dos recursos naturais é o de que, geralmente, são uma oferta fixa e somente são capazes de fornecer uma quantidade limitada de serviços em um dado período de tempo. Por isso faz-se necessário o emprego das técnicas das ciências administrativas e econômicas no processo de gerenciamento desses recursos notadamente aquelas que privilegiam a abordagem da sustentabilidade.

O uso racional do recurso torna-se a premissa inicial para a intervenção, quando o objetivo é a exploração deste. A gestão dos recursos sociais, culturais e naturais, bem como o planejamento do seu uso, deve valer-se de indicadores, notadamente àqueles que expressem o grau de sustentabilidade da atividade.

Os objetivos deste trabalho são: a) propor indicadores de sustentabilidade para 0 ecoturismo, considerando os componentes ambiental, social e econômico, aqui propostos como indicadores biofísicos (natural) e socioeconômicos (social e econômico) e; b) propor e testar modelo matemático para avaliação do nível de sustentabilidade ecoturística.

\section{Metodologia e métodos}

As fases deste roteiro ou estrutura para a definição de indicadores de sustentabilidade estão detalhadas em Filetto (2007), mas podem ser assim descritas, com a complementar visão de outros autores:

1) definição do sistema em análise: pode estar baseado em três níveis, segundo Yurjevic (1996), ou seja, nas perspectivas global, nacional, regional ou local, podendo ainda ser acrescentados os níveis de propriedade territorial, de sistemas na propriedade territorial, de ecossistema e de sistema de produção, dependendo dos interesses na avaliação;

2) identificação de categorias significativas: uma categoria é um aspecto do sistema, o qual deve ser significativo, do ponto de vista da sustentabilidade. Segundo Ávila (1989), Torquebiau (1989) e Camino e Muller (1993), para qualquer sistema e em qualquer nível de organização ou agregação, podem ser utilizadas as seguintes categorias:

a) recursos endógenos; b) operação do sistema;c) recursos exógenos e; d) operação dos sistemas exógenos. 
3) identificação de elementos significativos em cada categoria: um elemento é uma parte de uma categoria, significativa do ponto de vista da sustentabilidade.

\section{4) identificação e seleção de descritores/definição e obtenção de indicadores:}

a) descritores: descritores são características significativas de um elemento,

b) indicadores: indicador é uma medida de efeito da operação do sistema sobre o descritor (TORQUEBIAU, 1989).

c) identificação de descritores e indicadores

5) análise de indicadores: esta fase pode ser subdividida em: a) significado do indicador; b) o quê, como, onde e quando medir; c) insumos necessários para o cálculo; d) limitações do indicador; e) valores-limites do indicador; e f) apresentação e interpretação dos resultados;

6) procedimentos de monitoramento: estes procedimentos podem ser descritos para cada indicador selecionado ou para todo o conjunto.

No presente estudo, executou-se a metodologia descrita com algumas adaptações, procedendo-se da seguinte forma:

a) os itens 1 a 3 foram executados integralmente;

b) o passo 4 é o mais importante neste trabalho, pois é ele que concentra a maioria das operações para a definição dos indicadores, assim detalhadas:

i) enfoques para os indicadores com aplicações potenciais: monitorar o desempenho dos fatores biofísicos e socioeconômicos, possibilitando intervenções para a elevação dos níveis de sustentabilidade. Para chegar à conclusão de que isso seria possível, foi realizada uma ampla revisão de literatura, considerando todos os aspectos dos sistemas ecoturístico e turismo ecológico e as possibilidades de monitoramento dos indicadores;

ii) avaliação de enfoques para os indicadores: nesta fase de geração do maior número possível de indicadores, foram consideradas as peculiaridades dos sistemas ecoturísticos, principalmente levando-se em conta os componentes do sistema, ou seja, visitantes, moradores locais, fauna, flora, atrativos, infraestrutura e a sua composição no tempo e no espaço. Também foram definidas as diretrizes a partir das quais foram selecionados os indicadores de sustentabilidade, tendo como base Daniel (2000) e Filetto (2007), que realizaram uma significativa revisão sobre o tema. Um potencial indicador foi selecionado para a relação final, desde que se relacionasse com, pelo menos, uma das diretrizes. Salientase que os indicadores propostos neste trabalho não se assemelham aos propostos por Daniel (2000), no entanto, assemelham-se aos propostos por Filetto (2007); 
iii) seleção do grupo de descritores e indicadores mais significativos. Esta etapa foi dividida em duas fases: a) revisão de literatura: foram localizados descritores e indicadores significativos relacionados ao tema, o que permitiu uma primeira aproximação dos resultados, com o auxílio da parte correspondente aos componentes biofísicos e socioeconômicos; b) consulta a especialistas: um grupo de cinco pessoas ligadas a sistemas ecoturísticos teve a oportunidade de revisar e ampliar a lista de descritores e indicadores gerados a partir da revisão de literatura. Foi encaminhada uma lista com 220 indicadores a cada uma delas, solicitando que escolhessem aqueles que se relacionassem ao ecoturismo. Os indicadores escolhidos são apresentados nos resultados deste trabalho. Os escolhidos foram : 2 ecoturismólogos, 1 professor universitário educador físico e mestre em lazer, 1 professor universitário engenheiro florestal e doutor em ecologia e 1 educador especialista em ecoturismo e secretário municipal de turismo. $O$ critério de escolha destas pessoas baseou-se na experiência, na disponibilidade pessoal e na potencial confiabilidade das respostas.

Foram, ainda, realizadas visitas a sistemas ecoturísticos e de turismo ecológico, visando registrar impressões a respeito das características que poderiam se enquadrar nas diretrizes citadas no item (bii), ou que seriam úteis na definição dos indicadores mais significativos.

Foram considerados indicadores principais ou obrigatórios àqueles que se repetem nos vários sistemas, que sejam fundamentais para avaliação da sustentabilidade e que descrevam um amplo conjunto de aspectos técnicos, econômicos, sociais e ambientais. Este conjunto de indicadores deverá ter abrangência e profundidade, de modo que, com um pequeno número de indicadores, seja possível realizar uma avaliação de qualidade acerca da sustentabilidade do sistema e uma comparação entre os sistemas estudados (DEPONTI et al., 2006).

\section{Sustentabilidade, ecoturismo e indicadores}

O conceito de sustentabilidade, cuja origem remete às relações entre os seres humanos e o meio ambiente (recursos naturais), conforme Mangel et al. (1993), pode ser analisado sobre três diferentes aspectos:

- uso sustentável, que ocorre quando os seres humanos utilizam os recursos renováveis, permitindo que os processos naturais de reposição ocorram e assim o sistema passa renovar-se indefinidamente;

- crescimento sustentável, em que a questão básica que se impõe é se o crescimento econômico pode ser sustentável sem o controle do crescimento populacional e do consumo per capta de recursos que ocorrem, geralmente, desconsiderando a limitação de recursos e promovendo a degradação de hábitat; 
- desenvolvimento sustentável, o termo mais usado e o de mais difícil definição.

O conceito de sustentabilidade aplicado à prática de manejo pressupõe a necessidade de informações científicas como base para 0 processo de tomada de decisão, muito embora, de acordo com o exposto por Pitelka e Pitelka (1993), se reconheça que a decisão sobre o que fazer em relação a um problema ambiental envolva um julgamento de valor mais do que um julgamento científico, o que implica incluir a dimensão humana na resolução de problemas ambientais - seus desejos, motivações e necessidades - além de considerações econômicas e políticas.

Políticas públicas que estimulem e apóiem as iniciativas locais devem ocupar um papel muito importante no conjunto de políticas de desenvolvimento sustentável.

A solidariedade para com as gerações futuras só faz sentido como um complemento à solidariedade para com aqueles que hoje são marginalizados: o não-desenvolvimento, como uma solução para a preocupação ambiental global, não é aceitável devido ao seu custo social, exceto para áreas protegidas limitadas e particularmente frágeis.

$\mathrm{Na}$ perspectiva da prosperidade e do crescimento financeiro, há um fundamento lógico-econômico para a sustentabilidade. Como afirma McCool (1995 apud Fennell, 2002, p,12),

[...] quando as comunidades perdem o caráter que as torna distintas e atrativas para os não-residentes, elas perdem sua capacidade de disputar os rendimentos provenientes do turismo num mercado cada vez mais global e competitivo.

A sustentabilidade é, em toda parte, a perseguição de metas e a dimensão do progresso em sua direção. Não é mais apropriado aferir-se um desenvolvimento adequado por meio do produto físico ou do ápice econômico; deve haver também uma consideração de ordem social e de justiça social.

McCool (op. cit) acredita que para o turismo sustentável ter sucesso, devese considerar o seguinte:

a) como os turistas valorizam e usam os ambientes naturais;

b) como as comunidades são melhoradas por meio do turismo;

c) a identificação dos impactos sociais e ecológicos do turismo;

d) o gerenciamento desses impactos.

Como a conferência Globo 90 foi uma das forças iniciais e integrais a ligar o turismo ao desenvolvimento sustentável, seguiu-se a Globo 92 (HAWKES; WILLIAMS, 1993 APUD FENNELL, 2002), com a transposição dos princípios à prática, na implementação das medidas de sustentabilidade no turismo. Mesmo assim, nesta conferência, reconheceu-se que ainda 
havia muito a ser feito para a implementação dos princípios do turismo sustentável.

OMT (2003) deixa claro que a melhor maneira de alcançar o turismo sustentável é por meio de planejamento, desenvolvimento e gerenciamento cautelosos do setor turístico.

Assim, percebe-se que, no turismo, a sustentabilidade é discutida na perspectiva de indicadores e códigos de ética. Enquanto os indicadores usam variáveis identificadas para medir e monitorar os impactos do turismo, os códigos de ética ou de conduta usam listagens destinadas a evocar uma mudança de comportamento de grupos de investidores específicos, uma forma de consenso sobre o comportamento aceitável em um local de turismo.

Quando Dourojeanni e Pádua (2001) afirmam que o ecoturismo é uma das colunas do crescimento do turismo, acredita-se que a base para tal afirmação é a mais sólida do pensamento acadêmico. Segundo estes autores, o relatório de Blackwelder e Co., com base nos indicadores da Organização Mundial Do Turismo (OMT), apresentava que o turismo de aventura captou $10 \%$ do mercado de turismo e que esse setor cresce a um ritmo de $30 \%$ ao ano. Também informa que cerca de 65 milhões de observadores de pássaros (birds watchers) gastam, a cada ano, US\$ 5,2 bilhões para satisfazer seu prazer. O turismo internacional em países tropicais e com uma biodiversidade importante está crescendo rapidamente, inclusive no México, onde duplicou entre 1980 e 1995, passando de 11,9 a 20,1 milhões de turistas por ano.

Apesar dos dados apresentados, o ecoturismo ainda não conta, mundialmente, com estimativas muito precisas sobre o mercado que representa e sobre o seu potencial de crescimento. A Organização Mundial do Turismo (OMT) estima que $10 \%$ dos turistas em todo o mundo tenham como demanda destinos ecológicos. A World Travel e Tourism Council (WTTC) prevê que o ecoturismo represente, atualmente, de $5 \%$ a $8 \%$ do turismo mundial. Esses valores representariam algo entre US\$170 bilhões e US\$ 272 bilhões. A WTTC projetava para o ecoturismo, $20 \%$ do volume total do turismo mundial em 2005 (IGLESIAS, 2000).

A necessidade de agregar valores (sociais e ecológicos) às áreas naturais é, sem dúvida, um desafio, pois, além de garantir a sustentabilidade é possível também atribuir ações que visem o manejo das mesmas. Sem dúvida, a atribuição de valores a um dado ecossistema está diretamente relacionada às suas "funções ambientais", isto é, a capacidade de fornecerem "bens e serviços" que satisfaçam, direta ou indiretamente, as necessidades humanas (COSTANZA, 1994).

No ecoturismo, uma forma de turismo na qual dá-se consideração máxima à conservação da natureza e à educação dos visitantes em relação a ela, deve ser planejada de acordo com certos princípios relacionados à conservação e à construção de instalações de pequena escala. As comunidades existentes devem ser integradas dentro do planejamento do ecoturismo. Há muitas outras formas de turismo, para as quais as áreas locais podem apresentar potencial, sendo necessários diversos estudos durante o seu planejamento (OMT, 2003). 
O ecoturismo, em particular, tem potencial para o desenvolvimento em áreas naturais que ofereçam ambientes naturais ecologicamente interessantes, as quais, muitas vezes, estão combinadas a colônias de povos étnicos tradicionais. Por sua tendência normal à pequena escala, o ecoturismo, geralmente, pode ser praticado na esfera dos recursos locais, mas, em muitos casos, é necessária a assistência técnica à comunidade local, como forma de garantir o desenvolvimento e o gerenciamento adequados. Além disso, pode haver a necessidade de algum tipo de assistência financeira para auxiliar as comunidades a se desenvolverem neste aspecto (OMT, 2003).

Para Davenport et al. (2002), o ecoturismo é freqüentemente saudado como um dos poucos exemplos indiscutíveis de desenvolvimento sustentável que funciona, porque não apenas ajuda a assegurar a preservação in situ das áreas selvagens, mas também gera retorno econômico a partir das terras postas de lado para conservação. Além disso, o ecoturismo ajuda a educar o público em geral com relação a questões conservacionistas e cria uma aliança entre negócios e conservação.

Uma outra definição desses autores identifica uma diferença conceitual entre ecoturismo e turismo na natureza. Reconhecendo as dificuldades em definir o turismo na natureza, eles estabeleceram um escopo estreito e outro mais amplo para essa definição. O mais estreito, dizem eles, refere-se aos operadores que promovem excursões orientadas à natureza: o mais amplo, entretanto, aplica-se ao turismo que utiliza os recursos naturais, inclusive praias e paisagens campestres.

Definem o turismo na natureza como aquele que "focaliza principalmente os recursos naturais relativamente intocados, como parques $e$ áreas naturais, pantanais, reservas selvagens e outras áreas de flora, fauna e habitantes protegidos" (p.34). Nessa perspectiva, parece que há um certo consenso, na literatura que descreve o ecoturismo, em considerá-lo como parte de um turismo mais amplo, baseado na natureza. Isso se torna evidente na discussão feita por Goodwin (1996 apud FENNELL, 2002), o qual escreveu que o turismo na natureza:

Engloba todas as formas de turismo - turismo de massa, turismo de aventura, turismo de baixo impacto, ecoturismo que utilizam os recursos naturais de uma forma selvagem ou não desenvolvida - inclusive espécies, habitat, paisagens, atrações aquáticas de água doce e salgada. O turismo na natureza é a viagem selvagem (p.23).

$E$ inversamente, o ecoturismo é o turismo na natureza, de baixo impacto, que contribui à manutenção de espécies e habitats diretamente, por meio de uma contribuição à conservação e/ou indiretamente produzindo rendimentos para as comunidades locais, para que elas valorizem e, portanto, protejam suas áreas herdadas de vida selvagem como fonte de renda (Goodwin, 1996 apud Fennell, 2002). Beni (2002, p.9) conceitua "turismo ecológico" como 
deslocamento de pessoas para espaços naturais, com ou sem equipamentos receptivos, motivados pelo desejo/necessidade de fruição da natureza, observação passiva da flora, da fauna, da paisagem e dos aspectos cênicos do entorno. Neste sentido, pode ser também chamado de Turismo de natureza, ou Turismo Verde.

Inclui, também, aquelas pessoas que buscam uma observação participante e interativa com 0 meio natural, na prática de longas caminhadas, escaladas, desbravamentos e aberturas de trilhas, rafting e de outros esportes radicais, para os quais a natureza é apenas o pano de fundo para o desafio de superar limites físicos de tolerância como canyoning, off road, rapel e caving. Nesse sentido, pode-se também confundir com o chamado turismo de aventura e se inserir, ainda, no turismo desportivo, como nos jogos da natureza.

Irving (2002) ressalta que o ecoturismo é uma alternativa econômica de baixo impacto que, se bem planejada, ordenada, operada e monitorada, tem condições de contribuir de maneira valiosa para sustentabilidade regional.

Para Fontes (apud VITORINO et al. 2003), o ecoturismo é, em grande parte das vezes, encarado unicamente como um nome atraente para uma atividade tradicional. Antes de ser um conceito em formação, é apenas de difícil aceitação pelo meio empresarial conservador. Por falta de uma visão realmente ecológica, que inclua também investimentos financeiros, estas atividades limitam suas expectativas de vida e se tornam lugares comuns, abrindo mão de seu único diferencial no mercado, o ambiente em si antes de ser profundamente alterado. Antes de qualquer coisa, trata-se de uma exigência que se faz sobre a atividade turística em prol do benefício de um número maior de pessoas presentes e futuras, sendo assim a exigência de uma postura eticamente correta, da mesma forma que é necessário em outros ramos da atividade humana.

Até que ponto a representação de uma atividade para a participação de pessoas que não vivem no ambiente pode promover a proteção da natureza e a valorização da cultura local?

Ocorre uma encenação que não é mais própria da vida tradicional das pessoas que estão representando aquele espetáculo, mas que é comprada pelos chamados "turistas ecológicos". Estas atividades perdem o seu valor, deixando de serem práticas comuns.

Portanto, o uso pela atividade turística do resultado aparente dessa relação deve ser considerado dentro dos limites dessa atividade.

Outra questão é a forma como é avaliada a sustentabilidade da atividade. A avaliação é feita no momento do consumo, é esquecida a produção, isto é, a produção de uma paisagem a ser consumida; a produção de bens a serem consumidos pelos turistas nos locais visitados (por exemplo: comidas industrializadas, bebidas, equipamentos em geral máquinas fotográficas, filmadoras, apetrechos de caminhada etc. - veículos 
movidos a motor de explosão). Enfim, a produção, que é destrutiva, não conta na avaliação da sustentabilidade da atividade.

Cintra (2006) mostra a predominância dos indicadores ambientais no conjunto dos indicadores de sustentabilidade para o ecoturismo e turismo rural, não evidenciando nenhum indicador relativo aos fatores exógenos à atividade.

Entende-se que um conjunto de indicadores adequadamente estabelecidos é uma das melhores técnicas para se acompanhar todas as fases de um planejamento ecoturístico, pois possibilita avaliar as condições de produção e consumo (do ecoturismo) atuais e acompanhar, ao longo do tempo, a evolução rumo à sustentabilidade.

O mundo vê, hoje, o ecoturismo como uma forma de se alcançar altos lucros. Entretanto, tal concepção gera preocupação de não se ter a sustentabilidade tanto cultural, social, natural e econômica do local onde se vai desenvolver a atividade. Pois, sem um planejamento adequado, as conseqüências serão impactos negativos para a comunidade receptora e para o ecossistema local. A atividade ecoturística deve levar em consideração um planejamento adequado para o local, que contribuirá para a diminuição dos impactos negativos e da geração de impactos positivos.

Segundo a Conferência Preparatória para o Ano Internacional do Ecoturismo em 2002 (WWF, 2005), as operações de ecoturismo podem causar impactos negativos em populações locais. $O$ turismo pode elevar 0 custo de vida, forçar a população a se mudar para outros locais e, ainda, as políticas restritivas podem fazer com que os negócios locais migrem para outras áreas. O ecoturismo realizado em áreas protegidas deve trazer a solução de conflitos entre as populações locais e demais partes interessadas, educação para os visitantes, além de receita para as comunidades locais. É do interesse e vantagem de todos que as operações de turismo realizadas na natureza sigam adotando os princípios do ecoturismo, de forma a garantir que as áreas sensíveis sejam conservadas e as comunidades locais respeitadas.

Ao se discutir indicadores, pode-se perceber a necessidade de que eles sejam desenvolvidos por (para e pelas) todas as partes interessadas. Em termos ambientais e de cultura, os destinos de ecoturismo tendem a ser áreas frágeis. Consequentemente, os contatos devem unir os interesses ambientais e do turismo.

Os governos precisam implementar um sistema de monitoramento em áreas com potencial de desenvolvimento. Devem ter também um plano de ação que responda a uma explosão de desenvolvimento em áreas ambientalmente sensíveis e cercadas de comunidades.

Muitos países em desenvolvimento têm alguma dificuldade em fornecer dados sobre oportunidades de investimentos, padrões e exemplos de boas práticas. Estas fontes de informação precisam estar disponíveis para todas as partes envolvidas e devem ser escritas em linguagem acessível aos públicos diversos.

No Brasil, os problemas com os impactos das visitações existentes em grande parte das áreas abertas ao uso público, não são sequer tratados. 
A limitação de recursos, equipamentos e, principalmente pessoal, é uma constante. Ainda, o desenvolvimento desordenado da recreação em unidades de conservação brasileiras compromete alguns dos objetivos para os quais elas foram estabelecidas.

No Art. $4^{\circ}$ do SNUC (Sistema Nacional de Unidades de Conservação - Lei $n^{\circ} 9.985$ de 18 de julho de 2000 ) seu $12^{\circ}$ objetivo diz, com relação aos objetivos das unidades de conservação:

favorecer condições e promover a educação e interpretação ambiental, a recreação em contato com a natureza e o turismo ecológico". O $13^{\circ}$ completa: "proteger os recursos naturais necessários à subsistência de populações tradicionais, respeitando e valorizando seu conhecimento e sua cultura e promovendo-as social e economicamente.

Os impactos ambientais negativos do turismo possuem uma característica: quase sempre são difíceis de sanear. Seabra (1998 apud MARINHO; BRUHNS, 2003, p.236) enfatiza que os impactos ambientais provocam:

A compactação do solo e processos erosivos; a fuga da fauna silvestre; a exposição das raízes das árvores às pragas; a poluição dos corpos líquidos, por meio do despejo de efluentes não tratados, pelos hotéis e pousadas e embarcações turísticas; os incêndios, provocados por fogueiras de acampamentos; a poluição sonora e atmosférica, pela presença de automóveis; os desvios de cursos de rios; a introdução de espécies exógenas; pichações em grutas, sítios arqueológicos etc.

Os impactos culturais e sociais sofridos pela comunidade envolvida no atrativo turístico merecem ser avaliados. Tanto é bom para a localidade a visitação turística, porque está gerando renda em diversas atividades econômicas como, também, se não houver um cuidadoso planejamento, gestão e monitoramento da prática turística, a "invasão" de turistas na localidade pode acarretar em diversos problemas, como, por exemplo, perda das tradições, dos costumes, aculturação, problemas de saneamento básico, problemas crescentes com drogas, prostituição, violência, etc.

Desse modo, a população vai passar a rejeitar o visitante, que vai optar por outro ponto turístico e, consequentemente, acarretará na queda da economia do local. Dessa maneira, chega-se à conclusão de que para o turismo ser sustentável, é preciso que se tome conhecimento, inicialmente, de quais são os impactos negativos que podem existir na prática e quais medidas existem para evitá-los ou minimizá-los.

O turismo sustentável, ao envolver-se com a problemática dos impactos ambientais, incorpora, na sua prática, planejamento e zoneamento que determine a capacidade de carga dos ecossistemas envolvidos. Não pode existir sustentabilidade na atividade turística se não houver equilíbrio 
ambiental. Então, o planejamento contribui para minimizar o impacto ambiental das atividades turísticas, procurando alternativas de recuperação das áreas degradadas e sua conservação.

O uso de indicadores ambientais, econômicos, socioculturais e de gestão para se avaliar tanto o processo de desenvolvimento participativo do turismo quanto a sustentabilidade da atividade, vem sendo apontado como uma forte estratégia para a gestão pública local eficiente.

Os impactos do turismo, positivos ou negativos, na organização social e na cultura das populações locais, no meio ambiente ou na economia podem ser monitorados e avaliados por mecanismos muitas vezes simples, que podem ser compartilhados com os diferentes setores de interesse turístico.

A etimologia e o conceito de indicadores indicam que o termo indicador é originário do Latim indicare, que significa descobrir, apontar, anunciar, estimar (HAMMOND et al., 1995). Entende-se por indicador aquela informação que explicita o atributo que permite a qualificação das condições dos serviços, e por índice o parâmetro que mede o indicador, atribuindo-lhe valores numéricos. Os indicadores são dados que permitem quantificar, qualificar ou mensurar algum elemento desejado, facilitando a compreensão dos dados, melhorando a qualidade de pesquisas. Os indicadores são fundamentais para tomadores de decisão e para a sociedade, pois permitem tanto criar cenários sobre o estado do meio, quanto aferir ou acompanhar os resultados de uma decisão tomada (FRANCA, 2001).

Para Sellitto e Ribeiro (2004), as dimensões podem ser representadas por valores numéricos, os indicadores, que podem assumir um valor contínuo, analógico ou discreto, por valores lógicos. Em qualquer caso, é possível encontrar no indicador uma estrutura de graduação que descreve a situação da dimensão perante um referencial. Diversos indicadores podem ser combinados e resumidos quantitativamente em índices. Do mesmo modo que os construtos, os indicadores podem fazer parte de esquemas teóricos que auxiliam o pesquisador a representar a realidade na qual os fenômenos de interesse se inserem.

Brenbrook e Groth III (1996) consideram que um indicador em si é apenas uma medida, não tendo poder de previsão ou, sendo uma medida estatística definitiva, tampouco uma evidência de causalidade. Para esses autores, os indicadores apenas constatam uma dada situação.

Conforme Camino e Müller (1993), não é possível o desenvolvimento de um indicador global, por isso é necessário buscar no tempo a evolução da sustentabilidade dos sistemas. Não há indicadores universais, pois estes podem variar segundo o problema ou objetivo da análise. Ainda segundo esses autores, os indicadores devem ser robustos e não exaustivos, ou seja, robustos no sentido de cumprirem com as condições descritas, serem sensíveis e apresentarem condições de mensuração, e não exaustivos referindo-se apenas ao sistema sob análise e considerando os custos e complicações relativas a um monitoramento de um conjunto muito extenso de indicadores. Como observado, não parece adequado o estabelecimento de um único conjunto de indicadores para avaliar qualquer sistema, porque os indicadores serão diferentes segundo o entendimento de sustentabilidade 
e conforme os parâmetros e descritores definidos. A clara definição do que é sustentabilidade irá estabelecer o processo de interpretação dos resultados obtidos com a leitura do indicador (MARZALL, 1999).

Para este estudo foram considerados indicadores principais ou obrigatórios aqueles que se repetem nos vários sistemas, que sejam fundamentais para avaliação da sustentabilidade e que descrevam um amplo conjunto de aspectos técnicos, econômicos, sociais e ambientais. Este conjunto de indicadores deverá ter abrangência e profundidade, de modo que, com um pequeno número de indicadores, seja possível realizar uma avaliação de qualidade acerca da sustentabilidade do sistema e uma comparação entre os sistemas estudados (DEPONTI et al., 2006).

\section{Desenvolvimento de Indicadores de Sustentabilidade para 0 Ecoturismo em Unidades de Conservação}

Como resultado principal da aplicação da metodologia proposta, obtiveram-se os indicadores listados na Tabela 1. Considerando as recomendações de Daniel (2000), de que o número de indicadores não deve ser exaustivo e eles devem referir-se apenas às categorias e aos elementos mais significativos, os resultados apresentaram-se muito amplos. No entanto, este número elevado de indicadores abrange grande parte do que é possível avaliar, em termos de sustentabilidade de sistemas ecoturísticos. Sobre este rol, o usuário terá a oportunidade de escolher apenas alguns itens que, segundo critérios específicos, determinados de acordo com suas próprias necessidades, sejam suficientes para a avaliação da sustentabilidade de um dado empreendimento (eco) turístico. Embora extensa, a quantidade de resultados que são apresentados na Tabela 1 não representam a totalidade da matriz de indicadores, posto que esta é inimaginável física e operacional (CAMINO; MÜLLER, 1993).

Em outra fase do desenvolvimento de indicadores para sistemas ecoturísticos, deverão ser acrescentadas novas diretrizes ou critérios, para selecionar um número mínimo essencial. Segundo Camino e Müller (1993), que trataram de sistemas genéricos, a quantidade ideal de indicadores de sustentabilidade encontra-se entre 6 e 8, porém, Silva e Mendes (2001), que trabalhou com indicadores para qualidade de destinos turísticos em Portugal, obteve 27 indicadores. Já Marangon (2005) determinou 51 indicadores de sustentabilidade para a Comunidade Serra Negra da APA de Garaqueçaba/SP.

Os indicadores de sustentabilidade para o ecoturismo encontram-se na Tabela 1. 
Tabela 1: Indicadores de sustentabilidade para o ecoturismo.

Table 1: Sustainability indicators for ecotourism.

ষ্ণ

Descritor

Indicador

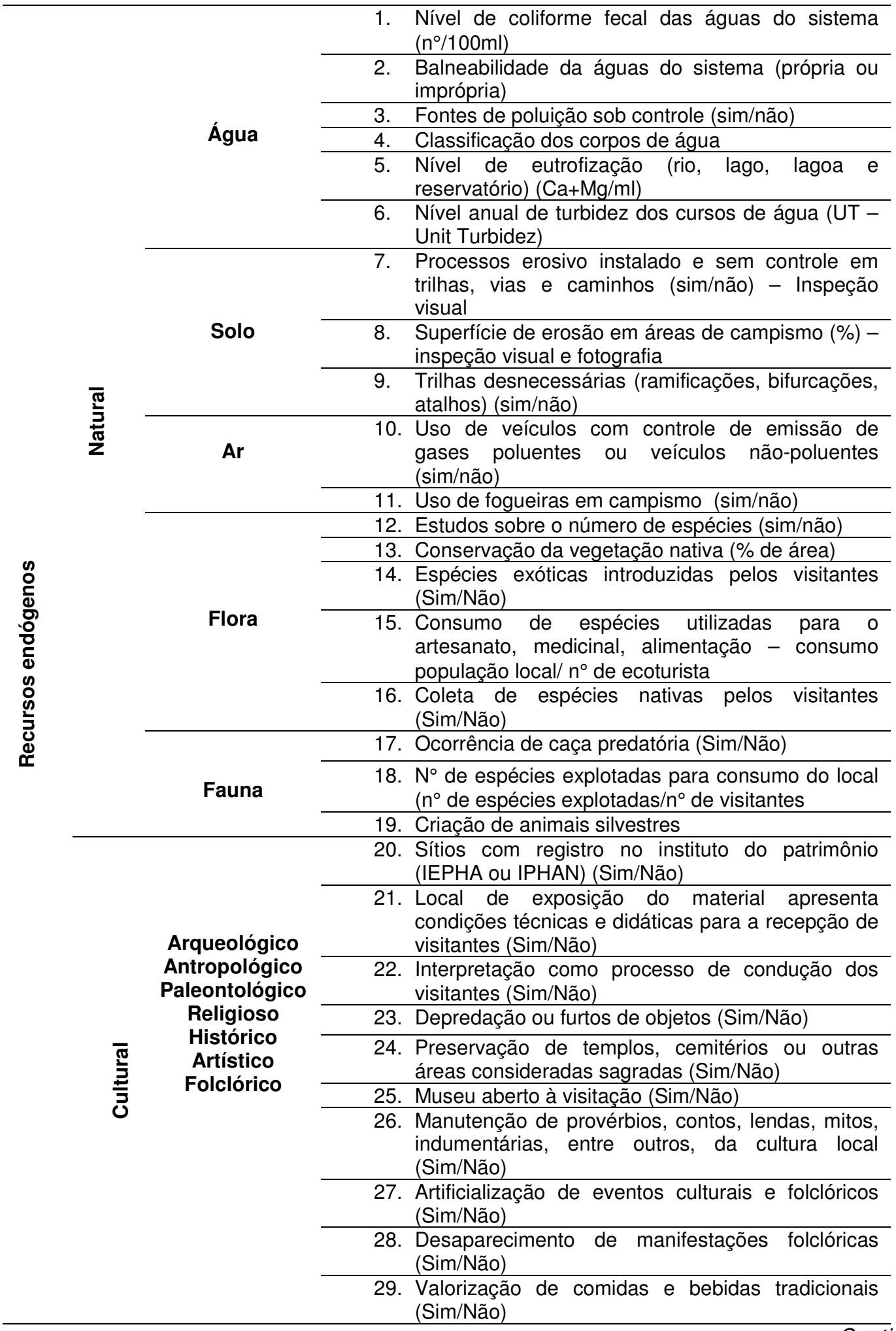

Continua... 
...continuação.

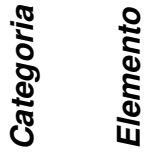

Descritor

Indicador

\begin{tabular}{|c|c|c|c|}
\hline & & & $\begin{array}{l}\text { 30. Paternalismo e assistencialismo nas relações } \\
\text { (Sim/Não) }\end{array}$ \\
\hline & & $\begin{array}{l}\text { Distribuição } \\
\text { de Renda e } \\
\text { Bens }\end{array}$ & $\begin{array}{l}\text { 31. Acesso da população local ao emprego } \\
\text { ecoturismo (\% emprego no ecoturismo/\% } \\
\text { empregados do local) }\end{array}$ \\
\hline & & & 32. Respeito à legislação trabalhista (Sim/Não) \\
\hline & & & $\begin{array}{l}\text { 33. Aumento da arrecadação de impostos na localidade } \\
\text { em função do ecoturismo (Sim/Não) }\end{array}$ \\
\hline & & & $\begin{array}{l}\text { 34. O morador local possui acesso ao processo de } \\
\text { planejamento do ecoturismo (Sim/Não) }\end{array}$ \\
\hline & & & $\begin{array}{l}\text { 35. Reforço do sentimento de identidade do morador } \\
\text { local(Sim/Não) }\end{array}$ \\
\hline & & Participação & $\begin{array}{l}\text { 36. Troca de experiências entre o morador local e o } \\
\text { visitante (Sim/Não) }\end{array}$ \\
\hline & & & $\begin{array}{l}\text { 37. Engajamento do morador local no ecoturismo } \\
\text { (satisfação) - por questionários }\end{array}$ \\
\hline & & & $\begin{array}{l}\text { 38. Programas de formação profissional para o morador } \\
\text { local relativo ao ecoturismo (Sim/Não) }\end{array}$ \\
\hline & & & 39. Aumento das ocorrências policiais (Sim/Não) \\
\hline & & Segurança & 40. Aumento das ocorrências de acidentes (Sim/Não) \\
\hline 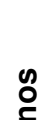 & $\begin{array}{l}\frac{\pi}{0} \\
\text { கூ }\end{array}$ & & $\begin{array}{l}\text { 41. Capacidade de carga das unidades de saúde }\left(n^{\circ} \text { de }\right. \\
\text { atendimentos de locais } / n^{\circ} \text { de atendimentos de } \\
\text { visitantes) }\end{array}$ \\
\hline & & & 42. Melhoria da infra-estrutura de saúde (Sim/Não) \\
\hline 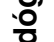 & & Saúde e & 43. Aumento do volume de lixo (Sim/Não) \\
\hline & & saneamento & 44. Reciclagem do Lixo (Sim/Não) \\
\hline \& & & & 45. Lixo nos atrativos (Sim/Não) \\
\hline क्ष & & & 46. Água em condição de consumo (Sim/Não) \\
\hline 己े & & & 47. Tratamento de efluentes (Sim/Não) \\
\hline$\underset{\varpi}{\varpi}$ & & & $\begin{array}{l}\text { 48. Escassez de água nos períodos de pico de visitação } \\
\text { (Sim/Não) }\end{array}$ \\
\hline & & & 49. Contaminação dos corpos de água (Sim/Não) \\
\hline & & Estado & $\begin{array}{l}\text { 50. Participação do poder público nas questões do } \\
\text { ecoturismo (Sim/Não) }\end{array}$ \\
\hline & & & 51. Desalojamento de moradores locais (Sim/Não \\
\hline & & & $\begin{array}{l}\text { 52. Especulação imobiliária eleva os preços das } \\
\text { moradias (Sim/Não) }\end{array}$ \\
\hline & & Habitação & $\begin{array}{l}\text { 53. Confinamento de moradores locais em locais mais } \\
\text { pobres e distantes (Sim/Não) }\end{array}$ \\
\hline & & & $\begin{array}{l}\text { 54. Escassez de moradias em função do ecoturismo } \\
\text { (Sim/Não) }\end{array}$ \\
\hline & & $\begin{array}{l}\text { Alocação dos } \\
\text { recursos }\end{array}$ & $\begin{array}{l}\text { 55. Consumo de produtos de produção local (consumo } \\
\text { total/consumo de produtos da localidade) }\end{array}$ \\
\hline & $\stackrel{\text { OOU }}{\mathrm{E}}$ & Gerenciamen & $\begin{array}{l}\text { 56. Plano de manejo ou desenvolvimento do ecoturismo } \\
\text { (Sim/Não) }\end{array}$ \\
\hline & $\stackrel{\circ}{\circ}$ & $\begin{array}{l}\text { to dos } \\
\text { recursos }\end{array}$ & $\begin{array}{l}\text { 57. Unidade de conservação com Plano de Manejo } \\
\text { (Sim/Não) }\end{array}$ \\
\hline & & & $\begin{array}{l}\text { 58. Secretaria de turismo ou meio ambiente na } \\
\text { administração municipal (Sim/Não) }\end{array}$ \\
\hline
\end{tabular}

Continua... 
...continuação.

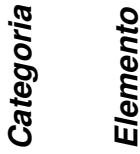

Descritor

Indicador

\begin{tabular}{|c|c|c|}
\hline & & $\begin{array}{l}\text { 59. } N^{\circ} \text { de veículos dos locais } / \mathrm{n}^{\circ} \text { de veículos de } \\
\text { visitantes }\end{array}$ \\
\hline & & $\begin{array}{l}\text { 60. Restrição do uso de veículos automotores } \\
\text { (Sim/Não) }\end{array}$ \\
\hline$\frac{\mathrm{t}}{\mathrm{0}}$ & & $\begin{array}{l}\text { 61. Uso do transporte coletivo pelo visitante (usuários } \\
\text { em dias normais/usuários em dias de pico) }\end{array}$ \\
\hline 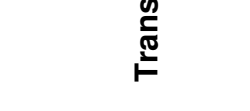 & Veículos & $\begin{array}{l}\text { 62. Condições de trafegabilidade dos veículos } \\
\text { automotores a serviço do ecoturismo (vazamentos } \\
\text { de óleos e combustíveis, segurança) (Sim/Não) }\end{array}$ \\
\hline & & 63. Congestionamentos (Sim/Não) \\
\hline & & $\begin{array}{l}\text { 64. Uso de veículos que causem danos ao ambientes } \\
\text { (erosão, poluição sonora, do ar) (Sim/Não) }\end{array}$ \\
\hline & & $\begin{array}{l}\text { 65. Conservação e economia do consumo de energia } \\
\text { não renovável (Sim/Não) }\end{array}$ \\
\hline & & 66. Conservação e economia no consumo de água \\
\hline & & $\begin{array}{l}\text { 67. Programa de combate ao desperdício de alimentos } \\
\text { (Sim/Não) }\end{array}$ \\
\hline है & Conservação & $\begin{array}{l}\text { 68. Uso de materiais de construção de baixo impacto } \\
\text { (Sim/Não) }\end{array}$ \\
\hline$\frac{\pi}{\mathbb{\pi}}$ & & $\begin{array}{l}\text { 69. Arquitetura privilegiando os fatores térmicos e de } \\
\text { iluminação do ambiente (Sim/Não) }\end{array}$ \\
\hline 운 & & $\begin{array}{l}\text { 70. Tratamento ou destinação correta dos efluentes e } \\
\text { resíduos sólidos (Sim/Não) }\end{array}$ \\
\hline & Localização & 71. Arquitetura condizente com o ambiente (Sim/Não) \\
\hline "ü & & $\begin{array}{l}\text { 72. A estrutura, seja hotel ou camping, esta instalada } \\
\text { em local adequado às normas ambientais e de } \\
\text { ocupação do solo (Sim/Não) }\end{array}$ \\
\hline & & 73. Privilégio do uso dos produtos locais (Sim/Não) \\
\hline & & 74. Cozinhas com uso de energia renovável (Sim/Não) \\
\hline 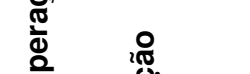 & & $\begin{array}{l}\text { 75. Tratamento ou destinação correta de efluentes e } \\
\text { resíduos sólidos (Sim/Não) }\end{array}$ \\
\hline 政 & Restaurantes & 76. Desperdício de alimentos (Sim/Não) \\
\hline$\underline{\complement}$ & e outros & $\begin{array}{l}\text { 77. Destinação do excedente às populações carentes } \\
\text { (Sim/Não) }\end{array}$ \\
\hline & & 78. Elevação dos preços (Sim/Não) \\
\hline & & 79. Escassez de produtos (Sim/Não) \\
\hline & $\begin{array}{l}\text { Mercado } \\
\text { Local }\end{array}$ & 80. Aumento da venda de produtos do local (Sim/Não) \\
\hline & Guias & $\begin{array}{l}\text { 81. Os guias e condutores do ecoturismo são da } \\
\text { localidade (Sim/Não) }\end{array}$ \\
\hline 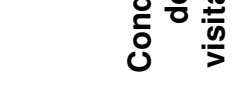 & & 82. Os guias são devidamente treinados (Sim/Não) \\
\hline$\frac{\pi}{3} \stackrel{\infty}{2}$ & & $\begin{array}{l}\text { 83. Danos por uso incorreto de carbureteira - } \\
\text { iluminação com carbureto para espeleologia } \\
\text { (Sim/Não) }\end{array}$ \\
\hline$\sigma \pm$ & & $\begin{array}{l}\text { 84. Dano visual pelo uso de ancoragens fixas em } \\
\text { escalada (Sim/Não) }\end{array}$ \\
\hline 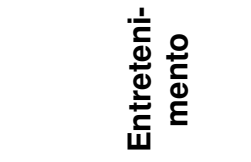 & STlios & 85. Artificialização de atividades tradicionais (Sim/Não) \\
\hline
\end{tabular}

Continua... 
...continuação.

:

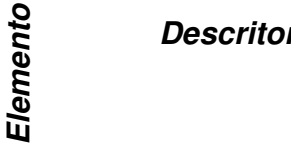

Indicador

\begin{tabular}{|c|c|c|c|}
\hline \multirow{12}{*}{ 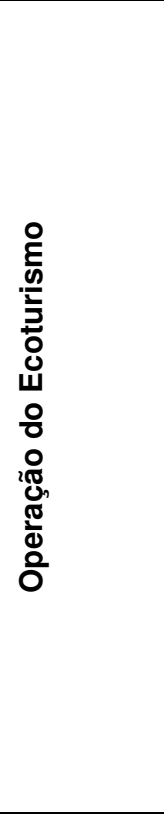 } & \multirow{12}{*}{ 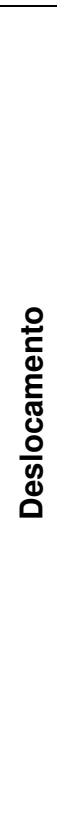 } & Caminhadas & $\begin{array}{l}\text { 86. Uso de trilhas não autorizadas (Sim/Não) } \\
\text { 87. Animais com problemas sanitários (Sim/Não) }\end{array}$ \\
\hline & & \multirow[t]{2}{*}{ Cavalgadas } & $\begin{array}{l}\text { 88. Uso abusivo de animais de montaria ou } \\
\text { carga (Sim/Não) }\end{array}$ \\
\hline & & & $\begin{array}{l}\text { 89. Animais contribuindo para disseminação de } \\
\text { espécies exóticas da flora em UCs (Sim/Não) }\end{array}$ \\
\hline & & \multirow[t]{2}{*}{ Bicicletas } & $\begin{array}{l}\text { 90. Uso de gritos ou sons elevados em trilhas } \\
\text { como aviso de presença (Sim/Não) }\end{array}$ \\
\hline & & & 91. Acidentes com ciclistas (Sim/Não) \\
\hline & & $\begin{array}{l}\text { Navegação } \\
\text { embarcada }\end{array}$ & 92. Excesso de passageiros (Sim/Não) \\
\hline & & \multirow[t]{2}{*}{ Escalada } & $\begin{array}{l}\text { 93. Danos à vegetação de encostas e paredões } \\
\text { (Sim/Não) }\end{array}$ \\
\hline & & & 94. Lixo nas vias de escaladas (Sim/Não) \\
\hline & & \multirow[b]{2}{*}{ Mergulho } & 95. Danos aos corais (Sim/Não) \\
\hline & & & $\begin{array}{l}\text { 96. Alimentação de animais aquáticos com a } \\
\text { finalidade de atraí-los (Sim/Não) }\end{array}$ \\
\hline & & Vôo livre & $\begin{array}{l}\text { 97. Pistas de lançamento e pouso em locais } \\
\text { adequados (Sim/Não) }\end{array}$ \\
\hline & & $\begin{array}{c}\text { Vela, } \\
\text { windsurf, } \\
\text { parasail }\end{array}$ & $\begin{array}{l}\text { 98. Marina, considerando as condições } \\
\text { ambientais para sua instalação (Sim/Não) }\end{array}$ \\
\hline $\begin{array}{l}\text { Recursos } \\
\text { Exógenos }\end{array}$ & & \multicolumn{2}{|c|}{ Não evidenciados como relevantes para o ecoturismo } \\
\hline $\begin{array}{c}\text { Operação } \\
\text { dos } \\
\text { sistemas } \\
\text { exógenos }\end{array}$ & \multicolumn{3}{|c|}{ Não evidenciados pela operação do ecoturismo } \\
\hline
\end{tabular}

Os indicadores de sustentabilidade para o ecoturismo referiram-se aos recursos endógenos:

- elemento natural - explicitado como sendo a água, o solo, o ar, a flora e a fauna, os quais evidenciaram 19 indicadores;

- elemento cultural - explicitados no patrimônio histórico, artístico, cultural e páleo-antropo-arqueológico, com 10 indicadores;

- elemento social - 25 indicadores;

- elemento econômico - 4 indicadores.

Os indicadores também referem-se à operação do ecoturismo no elementos de:

- transporte - 6 indicadores; hospedagem - 8 indicadores; alimentação - 8 indicadores; 
- guias e condutores - 2 indicadores; equipamentos - 2 indicadores; entretenimento - 1 indicador; deslocamento - 13 indicadores.

Os indicadores referentes aos recursos exógenos não foram considerados, por não estarem atrelados diretamente ao desempenho da atividade ecoturística, mas pode-se considerar o comportamento do ecoturista durante seu deslocamento entre a residência e o local de desenvolvimento do ecoturismo. Também podem-se considerar os aspectos de consumos deste visitante.

Outros aspectos para a apresentação de indicadores podem ser relativos a zonas de ocorrências, como nas zonas litorâneas - redução nos níveis de pesca, intensidade de uso de praias, acidentes relacionados com água e proporção de turistas, ocupação de mangues, entre outros, ou pequenas ilhas - disponibilidade de água doce, custo do fornecimento de água. Mas, a consideração para a generalização dos indicadores reside na abrangência da atividade ecoturística e suas áreas de ocorrência.

O indicador número 13 pode, por exemplo, ser transformado em medida qualitativa, em que o questionamento seria "se existem programas de conservação da vegetação nativa (Sim/Não).

\section{Considerações finais}

Não foram amplas as análises para a escolha dos indicadores, pois o objetivo foi o de demonstrar a aplicação do modelo matemático, os quais, no entanto, são relevantes.

Foram propostos 98 indicadores de sustentabilidade com potencial de serem utilizados em diferentes atividades ecoturísticas.

Concluiu-se que não existem indicadores universais, pois estes podem variar conforme o local de estudo, o problema ou o objetivo da análise. Os indicadores mostraram-se robustos no sentido de cumprirem com as condições descritas, serem sensíveis e apresentarem condições de mensuração, e não exaustivos referindo-se apenas ao sistema sob análise e considerando os custos e complicações relativas a um monitoramento de um conjunto muito extenso de indicadores.

Observou-se não ser adequado o estabelecimento de um único conjunto de indicadores para avaliar qualquer sistema, porque os indicadores serão diferentes, segundo o entendimento de sustentabilidade. 


\section{Referências bibliográficas}

ARRUDA, R. Populações tradicionais e a proteção dos recursos naturais em unidades de conservação. Ambiente e Sociedade, v.2, n.5, p.79-92, 1999.

ÁVILA, M. Sustainability in agroforestry. In: HUXLEY, P.A. (Ed.). Viewpoints and issues on agroforestry and sustainability. Nairobi, Kenya: ICRAF, 1989. 9p.

BENI, M.C. Análise estrutural do turismo. São Paulo: Senac, 2002.

BRENBROOK, C.M.; GROUTH III, E. Indicators of the sustainabilty and impacts of pest management systems, 1996. Disponível em: $<$ http://www.pmac.net/aaas.htm>. Acesso em: 28 ago. 2003.

CAMINO, R.; MÜLLER, S. Sostenibilidad de la agricultura y los recursos naturales: bases para estabelecer indicadores. San José: IICA, 1993. 134p. (Serie de Documentos de Programas IICA, 38).

COSTANZA, R. Economia ecológica: uma agenda de pesquisa. In: MAY, P.H.; MOTTA, R.S. (Org.). Valorando a natureza: análise econômica para o desenvolvimento sustentado. Rio de Janeiro: Campus, 1994. p.111-114.

DANIEL, O. Definição de indicadores de sustentabilidade para sistemas agroflorestais. 2000. 112p. Tese (Doutorado em Ciência Florestal)Universidade Federal de Viçosa, Viçosa, MG.

DAVENPORT, L.; BROCKELMAN, W. Y.; WRIGHT, P. C.; RUF, K. e DEL VALLE, F. B. R. Ferramentas de ecoturismo para parques. In: Terborg, J.; Van Schaik, C.; Davenport, L. e Rao, M. Tornando os parques eficientes: estratégias para conservação da natureza nos trópicos. Curitiba: Ed. da UFPR, 2002. p. 305-333.

DEPONTI, C.M.; ECKERT, C.; AZAMBUJA, J.L.B. Estratégia para construção de indicadores para avaliação da sustentabilidade e monitoramento de sistemas. Disponível em: $<$ http://www.emater.tche.br/docs/agroeco/revista/ano3 n4/artigo3.pdf>.

Acesso em: 2 ago. 2006.

DOUROJEANNI, M.J.; PÁDUA, M.T.J. Biodiversidade: a hora decisiva. Curitiba: UFPR, 2001. 308p.

FACO, R.A; NEIMAN, Z. A natureza do ecoturismo: conceitos e segmentação. In: NEIMAN, Z.; RABINOVICI, A. (Orgs.). Turismo e Meio Ambiente no Brasil. Barueri, SP: Manole, 2010.

FENNELL, D.A. Ecoturismo: uma introdução. São Paulo: Contexto, 2002. 281p.

FILETTO, F. Desenvolvimento de indicadores de sustentabilidade para o ecoturismo em unidades de conservação. Lavras: UFLA, 2007. 143p. Tese (Doutorado em Engenharia Florestal - Manejo Ambiental) Universidade Federal de Lavras

FRANCA, L.P. Indicadores ambientais urbanos. 2001. Disponível em: $<$ www.sustentabilidade.org.br/portal.html >. Acesso em: 21 dez. 2003. 
HAMMOND, A. et al. Environmental indicators: a systematic approach to measuring and reporting on environmental policy performance in the context of sustainable development. Washington: World Resources Institut, 1995.

IGLESIAS, W. T. . Análise Setorial Operadoras de Turismo e Agências de Viagem. São Paulo: Gazeta Mercantil S/A, 2000. 235p. (Matéria jornalística).

IRVING, M.A. Turismo, ética e educação ambiental - novos paradigmas em planejamento. In: IRVING, M.; AZEVEDO, J. Turismo, o desafio da sustentabilidade. São Paulo: Futura, 2002.

LUCHIARI, M.T.D.P. O lugar no mundo contemporâneo: turismo e urbanização em Ubatuba-SP. 2000. Tese (Doutorado)-IFCH Universidade de Campinas, SP.

MANGEL, M. Sustainability and Ecological Research. Ecological Application, v.3. n.4, p.573-575, 1993.

MARZALL, K. Indicadores de sustentabilidade para agroecossistemas. Porto Alegre: UFRS, 1999. 208p. Dissertação (Mestrado em Fitotecnia)Programa de Pós-Graduação em Agronomia, Universidade Federal do Rio Grande do Sul, Porto Alegre.

MARINHO, A.; BRUHNS, H. (Org.). Turismo, lazer e natureza. São Paulo: Manole, 2003.

OMT - ORGANIZAÇÃO MUNDIAL DO TURISMO. Guia de desenvolvimento do turismo sustentável. Porto Alegre: Bookman, 2003. $168 p$.

PITELKA, L.F.; PITELKA, F.A. Environmental decision making multidimensional dilemmas. Ecological Applications, v.3, n.4, p.566-568, 1993.

PNUMA. Caminhos para o Desenvolvimento Sustentável e a Erradicação da Pobreza - Síntese para Tomadores de Decisão. 2011. Disponível em:

$<$ http://www.pnuma.org.br/admin/publicacoes/texto/1101-

GREENECONOMY-synthesis PT online.pdf>

SELLITTO, M.A.; RIBEIRO, J.L.D. Construção de indicadores para avaliação de conceitos intangíveis em sistemas produtivos. Gestão e Produção, v.11, n.1, p.75-90, jan./abr. 2004.

SILVA, J.A.J.; MENDES, M.G. A qualidade dos destinos turísticos: dos modelos aos indicadores. Revista Portuguesa de Gestão, p.65-81, 2001.

TORQUEBIAU, E. Sustainability indicators in agroforestry. In: HUXLEY, P. A. (Ed.). Viewpoints and issues on agroforestry and sustainability. Nairobi, Kenya: ICRAF, 1989. 14p.

VITORINO, M.R.; FONTES, M.A.L.; FILETTO, F. Introdução ao turismo responsável. Lavras: UFLA/FAEPE, 2003. 72p.

WWF. Conferência preparatória para o ano internacional do ecoturismo em 2002. Disponível em: $<$ http://www.wwf.org.br/informa/doc/webconf ecotur.doc>. Acesso em: 23 fev. 2005. 
YURJEVIC, A. El desarrollo sustentable: uma mirada actualizada. Agroecologia y Desarrollo, Santiago, n.10, p.10-17, 1996

Ferdinando Filetto: Universidade Federal de Lavras, Lavras, MG, Brasil. E-mail: ffiletto@hotmail.com

Link para o currículo Lattes: http://lattes.cnpq.br/3898658861180461

Renato Luiz Grisi Macedo: Universidade Federal de Lavras, Lavras, MG, Brasil.

E-mail: rlgrisi@dcf.ufla.br

Link para o currículo Lattes: http://lattes.cnpq.br/6213575156024605

Data de submissão: 15 de dezembro de 2013

Data de recebimento de correções: 09 de fevereiro de 2015

Data do aceite: 09 de fevereiro de 2015

Avaliado anonimamente 